\title{
SIMULATION OF VIRTUAL TRIPWIRE USING REAL TIME VIDEO SURVEILLANCE FOR THE SECURITY OF RESTRICTED AREA
}

\author{
Adhi Dharma Wibawa ${ }^{\ddagger}$, dan Mauridhie Hery Purnomo ${ }^{\S}$
}

\begin{abstract}
ABSTRAK
Dalam dunia pengamanan, sistem video surveillance telah banyak digunakan pada segala bidang kehidupan untuk pengamanan berbagai properti yang berharga. Tetapi, pada kebanyakan sistem pengamanan yang telah ada, pengamanan hanya menggunakan teknologi video streaming yang sangat bergantung pada kedisiplinan tenaga penjaga atau pengamat tampilan dari sistem video surveillance. Sebagai ilustrasi, meskipun dalam sebuah sistem pengamanan telah dipasang sepuluh sistem video surveillance, tetapi kalau pada prakteknya hasil tampilan video streaming tersebut tidak diperhatikan oleh penjaga, maka hasilnya tetap saja nihil, artinya pencuri tetap saja bisa masuk. Dalam simulasi ini, akan dikembangkan sebuah sistem pengamanan berbasis video streaming tetapi dengan keunggulan mampu menimbulkan alarm jika pada tampilan video streaming tersebut terdapat hal-hal yang mencurigakan. Prinsip dasar dalam simulasi ini adalah algoritma image processing yang akan membedakan antara frame pertama dengan frame-frame berikutnya, yang dikerjakan secara real time yang menerapkan sebuah virtual tripwire atau garis batas maya pada sebuah daerah terlarang. Garis batas tersebut berbentuk kotak mengelilingi seluruh pinggiran pada tiap frame dalam sebuah aliran data video. Sistem akan membaca nilai setiap titik pada garis batas maya tersebut dan membandingkannya dengan nilai pada titik-tiitk yang sama pada frame-frame berikutnya secara kontinyu dan real time.
\end{abstract}

Kata kunci: real time video surveillance, virtual tripwire, real time image processing dan video pengamanan.

\section{ABSTRACT}

Recent development in the security world, video surveillance system has been used widely to protect the most valuable properties or restricted areas in the world. However, the old monitoring system usually only watch the Region of Interest (ROI) without any embedded systems that can trigger automatically the alarm when there are some suspected things happen. By using Virtual Tripwire, video surveillance system can protect safely and effectively the restricted area such as seaport, banking, jail, warehouse, automatic teller machine etc. Virtual tripwire is an algorithm to control the value of some certain pixels in fix position. Virtual tripwire is made of several points which make a rectangle in a captured frame. For the first time, system will take automatically one frame as reference by calculating each point in that rectangle and save them in some arrays. The second step is that in every second system will evaluate all points in the same position to measure weather there are some differences or not. These differences will trigger the alarm automatically. Virtual Tripwire is like a virtual border in the form of rectangle that can avoid everything to pass in a frame grabbed by producing sign.

Keywords: virtual tripwire, real time video surveillance, video security and real time image processing.

\section{PENDAHULUAN}

Dewasa ini penggunaan sistem pengamanan berbasis video telah berkembang hampir ke segala aspek kehidupan, mulai dari militer, perkantoran, perbankan, pendidikan, pasar dan lain sebagainya. Kebutuhan tersebut semakin meningkat tajam setelah terjadinya peristiwa 9/11 tahun 2001 di New York Amerika Serikat. Ketika ancaman terror dan keamanan akan property semakin mengkhawatirkan maka kebutuhan akan layanan keamanan dan perlindungan property yang handal juga akan semakin dibutuhkan (Bethlehem 2004).

Pemakaian video surveillance saat ini menuntut adanya perbaikan kualitas baik dalam hal tampilan gambarnya (detail gambar) ataupun pada proses peringatannya (warning system) yang meliputi : Network system, Information Distribution system dan warning system (Broadware 2005). Di Amerika Serikat bahkan dikenal adanya system berjangka video surveillance yaitu system pengamanan berbasis video dengan menerapkan beberapa tahapan pengiriman informasi. Sistem ini sekarang banyak diterapkan dalam aplikasi monitoring militer. Prinsip dasar dari sistem ini juga menggunakan video sebagai alat monitor dan pemrosesan sinyal secara realtime dari frame video, secara bagan kerja tampak seperti pada Gambar 1 (Zhihai He 2006).

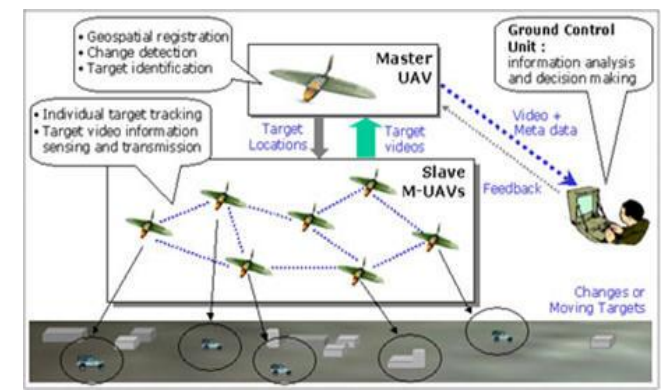

Gambar 1. Master-Slave Collaboration M-UAV Surveillance System Architecture.

\footnotetext{
* Jurusan Teknik Elektro, FT UHT, Jl. Arief Rahman Hakim 150, Surabaya (60111)

E-mail: arzabelva@yahoo.com

$\$$ Jurusan Teknik Elektro, FTI ITS, Jl. Arief Rahman Hakim, Surabaya (60111)

E-mail: hery@ee.its.ac.id
} 
Semenjak dunia menyatakan perang terhadap terorisme, level keamanan dan kewaspadaan pada tiap-tiap bandara maupun pelabuhan menjadi meningkat. Hal ini disadari karena arus barang, jasa dan bahkan manusia akan selalu melewati airport and seaport. Bahkan, dewasa ini telah dikembangkan sebuah standarisasi baru dalam hubungannya dengan management security menyusul maraknya aksi-aksi serangan terorisme di tempat-tempat umum (DuPont 2004). Keprihatinan dalam masalah security ini juga dipertegas dengan adanya kasus meninggalnya 17 warga Amerika Serikat dan melukai 35 lainnya dalam sebuah ledakan bom yang terjadi di dekat lambung kapal USS Cole di Yemeni Port of Aden pada bulan Oktober tahun 2000, di mana penyebabnya adalah tidak ada saksi mata yang memergoki dua orang telah menaruh bom di dekat badan kapal pada malam hari sebelumnya (Schwartz 2004).

Dari beberapa ulasan tadi dapat diambil sebuah benang merah bahwa penerapan Virtual tripwire terutama dalam tujuannya menangkal tindak pidana atau terorisme melalui real time video surveillance sangatlah penting dan urgent. Dengan Virtual Tripwire perlindungan terhadap public property ataupun privat property akan menjadi lebih baik. Berbagai bentuk kejahatan dan kriminal akan bisa kita cegah jika sistem pengamanan kita banyak menggunakan system real time video surveillance (Howard 2003). Di Negara-negara Eropa penerapan video surveillance telah menjangkau sampai ke pengawasan jalan raya, lampu lalu lintas bahkan mall-mall. Sebagaimana tampak pada Gambar 2 (Broadware 2005).

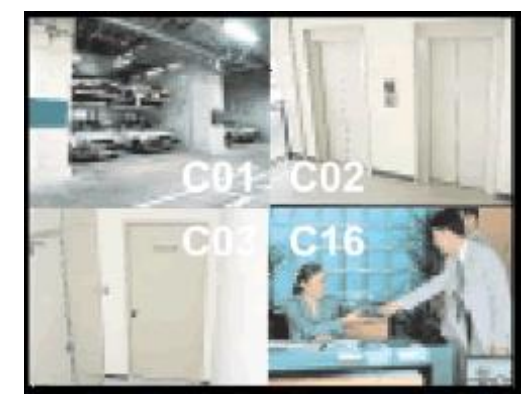

Gambar 2. Penerapan video surveillance di perkantoran dan lahan parkir.

(www.broadware.com)

Di dalam penelitian ini penerapan Virtual tripwire melalui video surveillance akan coba disimulasikan di dalam resitricted area untuk pengamanan brankas di sebuah bank. Meskipun dalam penerapannya nanti bisa sangat luas aplikasinya misalnya ketika kapal sedang bersandar dan tidak boleh ada kapal kecil lain yang mendekat maka video surveillance bisa digunakan sebagai virtual tripwire atau batas perjalanan kapal secara maya (DuPont 2004). Pengamanan dengan menggunakan virtual tripwire juga bisa digunakan untuk pengamanan area penjara (misalnya pada jam-jam tertentu tidak boleh ada orang yang lewat atau keluar masuk pada suatu gate tertentu) ataupun perlindungan ware house pada malam hari.

Dari latar belakang ini penulis tertarik untuk meneliti lebih jauh penerapan sistem pengamanan berbasis video melalui system real time video surveillance yang akan dilengkapi dengan system early warning system atau peringatan dini untuk pengamanan restricted area dengan menggunakan teknik Virtual tripwire atau garis batas maya.

\section{METODE PENELITIAN}

Metode yang digunakan dalam penelitian ini adalah image processing secara realtime dimana secara alur kerja akan tampak seperti Gambar 3.

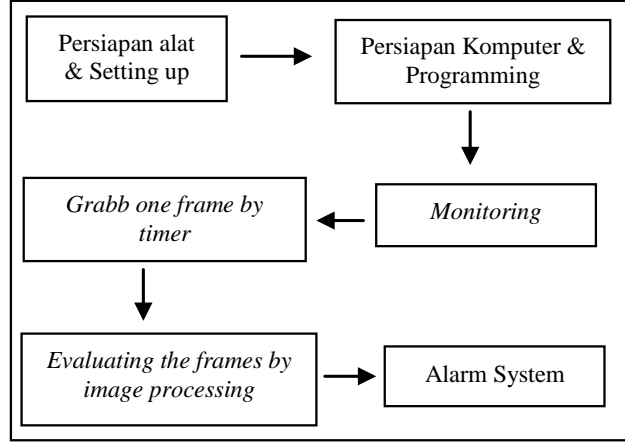

Gambar 3. Alur kerja penelitian virtual tripwire.

a) Persiapan alat dan Setting up: pada tahapan ini alat-alat yang dibutuhkan adalah 1 set PC dengan kamera video SONY TRV16e, kabel transfer video USB dan penerangan yang cukup.

b) Persiapan computer dan programming: pada tahap ini pada computer harus sudah terinstall USB Driver untuk transfer gambar dari kamera serta komponen Capture dan Grabbing dari software pemrograman Delphi.

c) Monitoring: Pada tahap ini programming sudah dijalankan dan kamera video sudah dion-kan. Pada saat transfer gambar video ke PC, pada programming tidak diset untuk menyimpan gambar tadi ke bentuk file AVI tetapi monitoring dilakukan melalui video streaming tanpa penyimpanan. Frame diambil dari video streaming tadi dan diolah oleh image processing.

d) Grabb one Frame by Timer: pada tahapan ini programming sudah diset untuk 
menggunakan timer dalam mengambil satu framenya untuk diolah. Satu putaran membutuhkan waktu kurang lebih 0.5 detik, sehingga maksimal waktu yang dibutuhkan untuk selalu mengambil 1 frame dari video streaming adalah 0.75 detik.

e) Evaluating the frame by image processing: Pada tahapan ini pada setiap putaran 0.75 detik akan dilakukan image processing untuk mengevaluasi adakah kejanggalan dalam tampilan gambar frame tersebut. Kejanggalan pada frame akan ditunjukkan dengan adanya perubahan nilai-nilai pixel pada titik-titik pengawasan. Titik-titik pengawasan akan tampak sebagaimana pada gambar berikut.

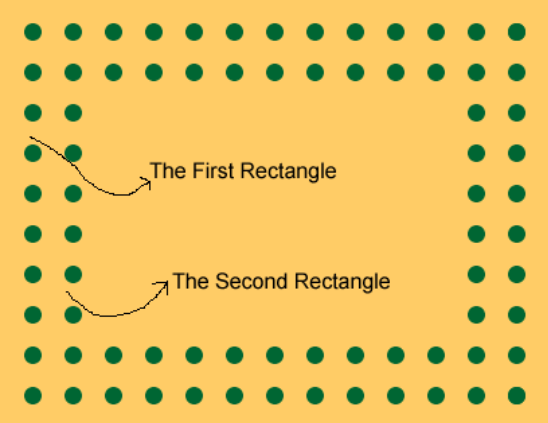

Gambar 4. Lokasi titik-titik pengawasan pada 1 frame pengamatan (320x240).

\section{ALGORITMA PEMROGRAMAN}

Alur berpikir dari System Virtual Tripwire adalah sebagai berikut:

a) Pada pengambilan satu frame telah ditentukan titik-titik control dengan posisi yang telah ditentukan, sebagaimana tampak pada Gambar 4. Nilai tiap pixel dalam titik-titik kontrol tersebut akan dievaluasi untuk pertama kalinya (sebagai standard awal). Nilai-nilai pixel tersebut akan disimpan ke dalam sebuah array tertentu.

b) Pada pengambilan frame setiap 0.3 detik, akan dilakukan evaluasi pada titik-titik kontrol yang sama. Hasil dari pengambilan frame berikutnya ini akan dibandingkan dengan nilai titik-titik kontrol yang pertama. Jika terjadi perubahan dalam beberapa titiknya, maka kondisi ini akan mentrigger alarm pengawasan untuk melakukan pemeriksaan atau pengawasan secara lebih intensif.

c) Proses pengaktifan alarm akan tergantung pada kondisi tertentu seperti: Jika terdapat lebih dari 3 atau 10 nilai titik kontrol yang berbeda dengan nilai titik-titik kontrol awal maka alarm akan diset aktif. d) Alarm akan diset dengan kondisi yang berbeda-beda tergantung perubahan yang terjadi pada titik-titik kontrol tersebut.

- Jika semua titik kontrol nilainya adalah 0 maka hal tersebut menunjukkan bahwa dalam ruangan tersebut kemungkinan terjadi bola lampu yang mati.

- Jika perubahan nilai titik-titik kontrol adalah partial maka sistem akan segera mengaktifkan alarm karena hal tersebut akan dipandang adanya intruder yang tidak diundang mencoba menerobos virtual tripwire (motion detection).

Pada simulasi ini juga akan ditampilkan prosentase perubahan frame. Pada perubahan yang terjadi pada point 4 alarm akan diset aktif tetapi dengan kondisi yang berbeda dari point 3 .

\section{HASIL DAN PEMBAHASAN}

Dari percobaan yang telah dilakukan, software yang telah dibangun mampu mendeteksi secara detail perubahan yang terjadi akibat adanya objek yang berusaha menerobos virtual tripwire yang sudah dibuat. Proses pengerjaannya adalah sebagai berikut:

a) Dari satu frame dengan ukuran $320 \times 240$ pixel, akan diletakkan satu titik pengontrolan pada setiap 10 pixelnya untuk membentuk virtual tripwire pertama. Hal yang sama juga akan dilakukan untuk membuat virtual tripwire kedua sehingga total titik-titik kontrolnya adalah :

- $\quad$ pada tripwire pertama : $(31$ X 2) $+(23 \mathrm{X} 2)$ $=62+46=108$ titik

- pada tripwire kedua : $(62 \times 2)+(46 \mathrm{X} 2)$ $=124+92=216$ titik

Secara lebih jelas ilustrasi peletakkan titik-titik kontrol adalah sebagai berikut:

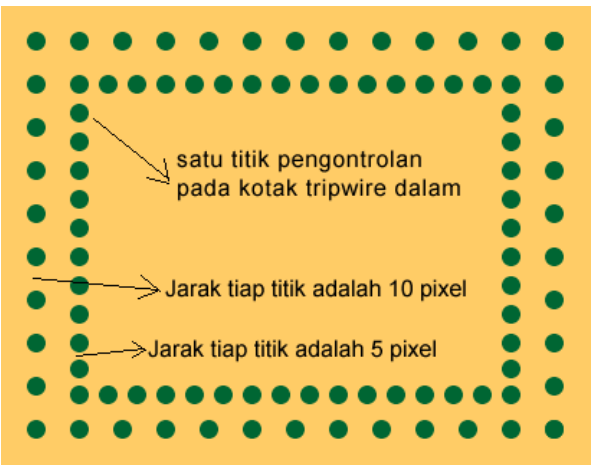

Gambar 5. Teknik peletakkan titik kontrol pada frame. 
b) Pada frame pertama akan disiapkan sebuah array dengan nama variable Dat1 sebanyak 324 data array yang didapat dari jumlah titiktitik yang membentuk kotak pertama (108 titik) dan titik-titik yang membentuk kotak kedua (216 titik).

c) Pada frame kedua juga telah disiapkan sejumlah array dengan nama variable Dat2 sebanyak 324 data. Pada proses evaluasi, yang dilakukan adalah membandingkan data yang terisi dari array 1 dan array 2 . Array 1 berisi informasi nilai Red atau $\mathrm{R}$ dari pixel tinjauan pada frame 1 dan array 2 berisi informasi nilai Red pada titik tinjauan dari frame 2. Jika hasil pembandingan menunjukkan bahwa terdapat lebih dari 3 titik yang memiliki nilai yang berbeda maka diasumsikan telah terjadi perubahan gambar antara frame 1 dengan frame 2 atau bisa juga dikatakan bahwa pada frame 2 ada objek yang berusaha menerobos virtual tripwire.

d) Pada kondisi ini, programming akan mentrigger alarm pusat untuk mengecek objek apa yang sedang masuk ke area of interest, apakah ada hal yang mencurigakan atau hanya gangguan serangga biasa.

e) Jika perubahannya terjadi secara bersamaan pada semua titik maka kondisi ini pun akan mentrigger alarm (dengan nada yang berbeda) ke pos pengawasan pusat.

Gambar tampilan program ketika dijalankan pertama kali adalah sebagaimana tampak dalam Gambar 6. Video Camera yang telah terpasang ke computer secara otomatis akan mengcapture gambar target (restricted area) dan menyimpannya dalam 1 frame sebagai standard nilai awal dari titik-titik kontrol.

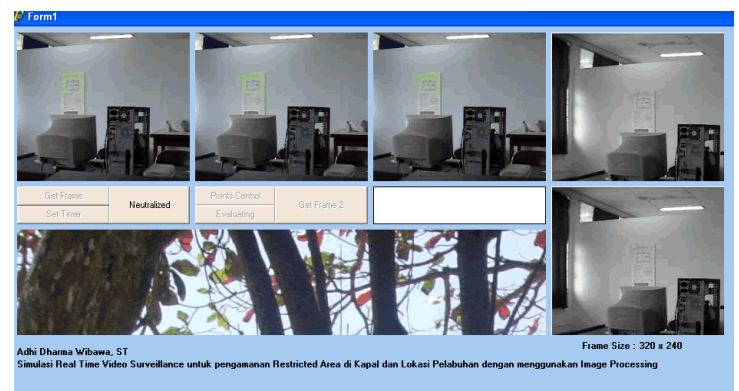

Gambar 6. Tampilan program untuk pertama kalinya.

Setelah nilai-nilai awal dalam bentuk array tersimpan, maka timer program akan diaktifkan. Timer ini akan otomatis selalu mengambil satu frame untuk diolah atau dievaluasi setiap 0.75 detik. Hasil evaluasi ini kemudian akan memutuskan adakah perubahan nilai titik-titik kontrol pada frame 2 perlu mendapatkan perhatian ataukah tidak. Tampilan program berikutnya seperti dalam Gambar 7 .

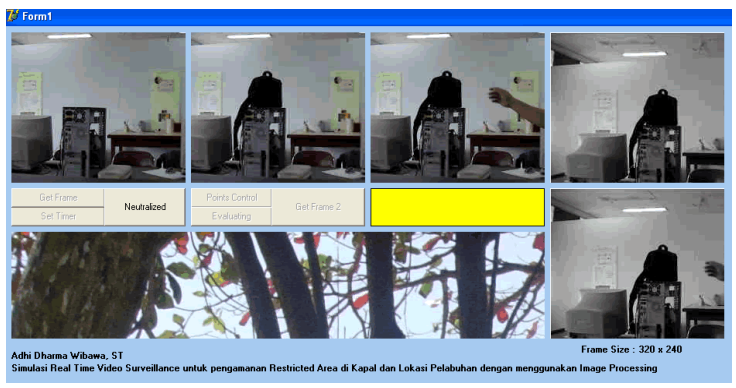

Gambar 7. Tampilan program untuk mendeteksi keganjilan.

Pada Gambar 7, tampak bahwa tas hitam tersebut coba diambil oleh seseorang maka gerakan tangan si pengambil tersebut terdeteksi melalui kamera video surveillance karena telah menerobos Virtual tripwire yang telah dibuat mengelilingi tepian gambar dan hal ini otomatis akan mentrigger sistem untuk mengaktifkan alarm bahwa ada sesuatu yang ganjil terjadi. Bentuk alarm juga ditunjukan dengan terjadinya perubahan warna pada shape box 1 menjadi kuning.

Hasil percobaan yang telah dilakukan bisa dilihat pada Table 1, dengan bentuk gangguan yang sengaja dibuat bervariasi, mulai dari gambar manusia, serangga kecoa, lampu senter dan bermacam-macam gangguan lainnya yang akan coba diujikan. Level alarm yang digunakan ada dua macam, yaitu level biasa (3 titik beda) dan level serius (10 titik beda). Pada level biasa diasumsikan gangguannya adalah berupa serangga, lampu mati atau hal-hal kecil lainnya. Pada level serius diasumsikan bahwa gangguannya adalah manusia atau sejenisnya. Representasi program atas pelevelan ini adalah pada warna shape1.brush yaitu mulai dari putih (normal), kuning (early warning) dan merah (serious warning).

Tabel 1. Hasil percobaan pada kondisi Indoor.

\begin{tabular}{|c|l|c|}
\hline No & \multicolumn{1}{|c|}{ Jenis Intruder } & $\begin{array}{c}\text { Level } \\
\text { Alarm }\end{array}$ \\
\hline 1 & Manusia lewat & Serius \\
\hline 2 & Tangan masuk ke area ROI & Serius \\
\hline 3 & $\begin{array}{l}\text { Kotak Stavolt di ambil oleh } \\
\text { seseorang }\end{array}$ & Serius \\
\hline 4 & $\begin{array}{l}\text { Monitor Komputer coba } \\
\text { dipindahkan }\end{array}$ & Serius \\
\hline 5 & $\begin{array}{l}\text { Tas Kamera coba diambil } \\
\text { dengan tangan manusia }\end{array}$ & Biasa \\
\hline 6 & $\begin{array}{l}\text { CPU coba dipindahkan } \\
\text { Biasa }\end{array}$ \\
\hline
\end{tabular}


Salah satu gambar lainnya hasil deteksi dini pada virtual tripwire dengan teknik video surveillance indoor adalah sebagaimana tampak pada gambar di bawah. Pada gambar (a) adalah proses awal ketika "barang yang berharga" sedang dalam pengawasan video surveillance. Gambar (b) adalah ketika terjadi proses pengambilan dan penukaran dengan barang yang sejenis tapi tidak sama (dengan harapan menguji kecepatan system dalam bereaksi). Hasilnya adalah system virtual tripwire mampu mendeteksi secara dini proses pengambilan itu bahkan sebelum si pengambil sempat selesai meletakkan benda keduanya. Semua proses ini hanya terjadi dalam waktu 1 detik.

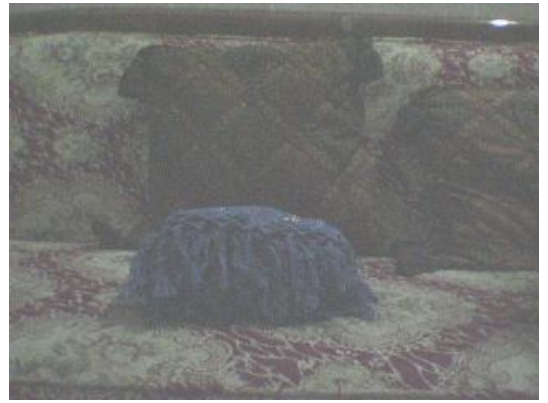

Gambar 8. (a)

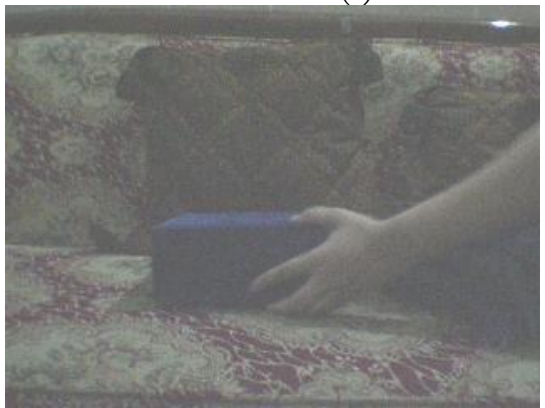

Gambar 8b. (b)

Gambar 8. (a) Proses awal pengawasan (b) Proses penukaran.

Secara hasil, penelitian ini telah mampu menunjukkan hasil yang akurat terutama dalam hal early warning system for security, yaitu alarm otomatis akan menyala ketika terjadi perubahan gambar pada frame 2 akibat menerobos virtual tripwire yang sudah dibangun di tepian gambar. Dari ke 6 percobaan yang telah dilakukan tidak satupun mengalami kegagalan atau luput dalam mendeteksi.

\section{SIMPULAN}

a) Simulasi system Virtual Tripwire dengan menggunakan teknik real time video surveillance berbasis programming ini telah mampu menunjukkan unjuk kerja yang tinggi dengan satu siklus perhitungan dikerjakan kurang dari 0.75 detik dan menggunakan standard batas aman adalah sejumlah 3 titik berbeda (level biasa) dan 10 titik berbeda (level serius) jika terdapat objek yang berusaha menerobos garis batas virtual yang sudah dibuat.

b) Pada beberapa percobaan yang telah dilakukan dengan menggunakan 324 titik kontrol, benda-benda yang relatif kecil masih tetap bisa dideteksi oleh sistem. Hal ini menunjukkan bahwa tingkat ketelitian system Virtual Tripwire sangat tergantung pada jumlah titik-titik kontrolnya. Semakin banyak jumlah titik-titik kontrolnya dan semakin kecil batas ambang jumlah titik yang digunakan maka ketelitiannya akan semakin tinggi.

c) Semakin banyak jumlah garis Virtual Tripwire yang diterapkan pada sebuah image maka system keamanan yang digunakan juga akan menjadi semakin ketat.

\section{DAFTAR ACUAN}

Anil, K.J. (1989), Fundamental of Digital Image Processing, New Jersey, Prentice Hall.

Bethlehem, D. (2004), Improving Homeland Security with IP Video Surveillance, USA Optibase, Video innovation.

DuPont. D.K. (2004), A Virtual Tripwire : Drawing the Line on Water, The Miami Herald.com. (Diakses Tgl : 12 Pebruari 2006). Gonzales, R.C. dan Woods, R.E. (2002), Digital Image Processing Second Edition, New Jersey, USA, Prentice Hall Inc.

Howard (2003), Automating Video Surveillance, www.MobsAutomating Video Surveillance.htm. (Diakses Tgl: 12 Pebruari 2006).

Jackson, W. (2004), Nighttime Surveillance. Government Computer News and Washington Technology, USA. (Diakses Tgl: 12 Pebruari 2006).

Murni, A. (1992), Pengantar Pengolahan Citra, PT. Elex Media Komputindo dan Pusat Antar Universitas Ilmu Komputer Universitas Indonesia, Jakarta.

Munir, R. (2002), Pengolahan Citra Digital dengan Pendekatan Algoritmik, Bandung, Bandung Informatika.

Nalwan, A. (1997), Pengolahan Gambar secara Digital, PT. Elexmedia Komputindo, Jakarta. 
Sakar, D. (2004), Plugging the Hole in Shipping - Federal, the State and Officials Work to Secure the Ports, Federal Computer Week. FCW.com. (Diakses Tgl: 13 Pebruari 2006).

Schwartz, K. (2004), Visual Analitics Tools

Sharpen Real Time Video Detection Systems, www.Govexec.com. (Diakses Tgl: 11 Pebruari 2006).

Wibawa, A.D., Mulyanto, E., dan Purnomo, M.H. (2005), 'Early Detection on the condition of Pancreas organ as the cause of Diabetes Mellitus by Iris Image Processing and Modified SOM Kohonen', International Federation of Medical and Biomedical Engineering (IFMBE), Proceeding, volume 12. ICBME 2005 Singapore. (Suntec City Singapore, 7-10 Desember 2005).
Wibawa, A.D. (2006), 'Simulasi Real Time Video Surveillance untuk Pengamanan Restricted Area di Kapal dan Lokasi Pelabuhan dengan Menggunakan Image Processing', Lomba Karya Tulis Ilmiah Bidang Kelautan, dalam rangka Dies Natalis Universitas Hang Tuah ke XXII 2006, Surabaya (Juara II).

www.objectvideo.com, (2006), Intelligence Video Surveillance Increases Security at Seaports, USA. (Diakses Tgl: 11 Pebruari 2006).

Diterima: 03 Oktober 2006

Disetujui untuk diterbitkan: 13 Desember 2006 